\title{
Utility and limits of biomass spectra: the nekton community sampled with the RMT 25 in the Scotia Sea during austral summer
}

\author{
Paul G. Rodhouse ${ }^{1}$, Uwe Piatkowski ${ }^{2}$, Eugene J. Murphy ${ }^{1}$, Martin G. White ${ }^{1}$, \\ Douglas G. Bone ${ }^{1}$ \\ ${ }^{1}$ British Antarctic Survey, Natural Environment Research Council, High Cross, Madingley Road, Cambridge CB3 0ET, \\ United Kingdom \\ ${ }^{2}$ Institut für Meereskunde an der Universität Kiel, Düsternbrooker Weg 20, D-24105 Kiel, Germany
}

\begin{abstract}
An RMT 25 opening/closing net was used to sample the nekton community at 2 stations in the ice free zone (IFZ) of the Scotia Sea (Stn 1 approximately 10 nautical miles south of the Antarctic Polar Front; Stn 2 on the edge of the South Georgia Shelf Break to the northwest of the island). Oblique hauls sampled $200 \mathrm{~m}$ depth layers to $1000 \mathrm{~m}$ during both day and night. Total and individual volumes of each species in each $200 \mathrm{~m}$ layer were measured by displacement. The data were used to generate biomass and numerical spectra for day and night at each station for the whole water column to $1000 \mathrm{~m}$. At both stations the relationship between $\log _{10}$ biomass density $(B / A)$ and $\log _{10}$ individual body mass $(M)$ were strongly positive. Slopes of the biomass spectra were not significantly different among the day and night stations and an overall regression showed that biomass density scaled as $M^{0.61}$. Analysis of biomass spectra revealed that although the species composition and biomass density varied between the 2 stations, energy turnover in the nekton community in the 2 areas was similarly dominated by animals of larger size. Considering energy turnover in terms of taxonomic groups revealed that Stn 1 turnover was dominated by tunicates (salps) followed by fish and cnidarians and at Stn 2 turnover was dominated by crustaceans followed similarly by fish and cnidarians. Use of biomass spectra in this case study was shown to enhance insight into the comparative function of 2 pelagic systems obtained using a conventional taxonomic approach. The analysis of biomass spectra in the absence of taxonomic data would have had limited value as it would not have emphasised the major difference between the 2 stations: the domination by tunicates, an energetic dead end, at Stn 1 and crustaceans, which are available to predators, at $\mathrm{Stn} 2$.
\end{abstract}

KEY WORDS: Biomass spectra $\cdot$ Nekton community $\cdot$ Southern Ocean

\section{INTRODUCTION}

Ecosystem dynamics in the ice-free zone (IFZ) of the Southern Ocean (Hempel 1985) has received little attention from marine ecologists by comparison with the seasonal pack-ice zone. The IFZ is generally less productive than the higher latitude oceanic systems in the Antarctic and the epipelagic community is dominated by copepods, small euphausiids and salps (Mackintosh 1934, Foxton 1966, Hempel 1985, Marchant \& Murphy 1994). However, within the IFZ there are locally dense concentrations of nektonic species, especially mesopelagic fish and epipelagic cephalopods (Rodhouse \& Yeatman 1990, Filin et al. 1991, Koslov et al. 1991, Rodhouse 1991) and it is likely that the contribution of mesopelagic fish, especially the myctophids, to energy flux in the IFZ has been greatly underestimated (Kock 1992). The myctophids and cephalopods are important prey for several species of seabirds and seals (Croxall et al. 1985, Adams \& Klages 1987, Rodhouse et al. 1987, 1990, 1992a, Hindell 1988, Ainley et al. 1991, Rodhouse \& Prince 1993, Ridoux in press) and there are known to be predator/prey relations between ommastrephid squids and myctophid 
fishes (Rodhouse et al. 1992b). The nektonic fishes and squids occur in sufficiently high concentrations to be the target of commercial fisheries or to have potential for future exploitation (Lubimova et al. 1983, Rodhouse 1990, Rodhouse et al. 1993). The IFZ appears to be locally productive so the production dynamics of the nekton is of ecological interest, especially from the perspective of sustainable resource management.

Gaining an understanding of the ecosystem dynamics in such systems is extremely difficult if attempts are made to define all the specific ecosystem connections. It has been shown that across a wide variety of ecological communities, values for rates of production, respiration and specific production (production/biomass) show consistent patterns of change with individual body mass (Banse \& Mosher 1980, Dickie et al. 1987). Patterns of rate process relations with body mass indicate that in animal communities, common mechanisms control the relationship between numbers and size of organisms (Boudreau et al. 1991). This provides an approach to the analysis of community production dynamics through the construction of biomass spectra. Spectral methods have been exploited for a number of applications in production ecology including questions of yield from fisheries in different ecosystems (Boudreau \& Dickie 1992). Studies of oceanic production ecology have shifted from the construction of species-based trophic networks for the analysis of community energetics, in favour of analysis of ecosystems on the basis of size and density. This approach avoids the various problems that have been encountered when employing Lindeman's (1942) trophic level concept for the calculation of energy flow though communities (Mann et al. 1989).

When logarithm of biomass density per unit area $(B / A)$ for a community is plotted as a function of the logarithm of individual body mass $(M)$, the slope of the fitted linear relationship indicates the relative contribution of different size groups of animals to the total biomass. Where the slope is negative, smaller sizes of animals, or species, dominate the biomass; where the slope is positive, large animals dominate. Boudreau \& Dickie (1989) have compiled data for production per unit area $(P / A)$ and biomass per unit area $(B / A)$ for a large group of invertebrates and a large group of fishes. They show that a logarithmic transformation generates a linear relationship between $P / B$ and $M$ which can be expressed as:

$$
\log _{10}\left(\frac{P}{B}\right)=a+b \log _{10}(M)
$$

which can be related to areal biomass and production by:

$$
\frac{P}{B}=\frac{P}{A} \times \frac{A}{B}
$$

For a large group of invertebrates $P / B$ has been shown to scale as $M^{-0.38}$ and for fish as $M^{-0.33}$. Although the intercepts (a) for these 2 groups differ, the close similarity of the values for the exponents $(b)$ suggests that for practical purposes $P / B$ scales as approximately $M^{-0.36}$. Thus, in a community in which the linear relationship for $\log _{10} B / A$ with $\log _{10} M$ gives a slope of 0.36 the rate of production per unit area $(P / A)$ per size group, or species, would be independent of individual body mass. If $B / A$ scales as $M^{>0.36}$ then $P / A$ per size group, or species, would increase with individual body mass.

Production shows an approximate 1:1 linear (logtransformed) relationship with respiration for increasing animal size for various groups of organisms (McNeill \& Lawton 1970, Humphreys 1979, Boudreau \& Dickie 1992). So in place of direct measurements of energy flow per unit area for all the species in a community, production can be estimated from the relationships of biomass or numerical population density $(B / A$ or $N / A$ ) and individual body mass $(M)$. Because in most animals the metabolic rate of an individual (rate of heat production, $U$ ) scales as approximately $M^{0.75}$ (Peters 1983) the total energy use (power) per unit area $(E / A)$ for a given size group or species is given by:

$$
\frac{E}{A}=\frac{B}{A} \times M^{-0.25}=\frac{N}{A} \times M^{0.75}
$$

So in a community in which the linear relationship for $\log _{10} B / A$ with $\log _{10} M$ gives a slope of 0.25 the rate of energy intake per size group $(E / A=B / A \times U / M)$ is independent of individual body mass. If $B / A$ scales as $M^{>0.25}$ then the rate of energy intake per size group or species $(E / A=B / A \times U / M)$ increases with individual body mass. The above relationships can be used to consider the production of a nektonic system analysed in terms of size.

The underlying allometric relationships between individual body mass and physiological rate processes are empirical but well established in several major marine groups including the crustaceans, molluscs and fish (Ivleva 1980, Bayne \& Newell 1983, Jobling 1993). They are far less well documented for other phyla, especially the gelatinous forms such as the tunicates, coelenetrates and ctenophores, but Ikeda (1985) found a mass exponent for oxygen consumption of 0.79 when data for 143 pelagic species from 17 phyla were pooled in the same regression analysis suggesting a general allometric relationship among the pelagic species.

Predation processes in the pelagic nekton system of the Antarctic and other oceanic regions have proved to be largely intractable but the biomass spectra approach provides an opportunity to examine the dynamics of this system. Construction of biomass and 
numerical spectra for nekton communities allow the size groups, or species, of animals which contribute most to production and energy flux through the community to be identified. The pelagic environment is generally thought to be amenable to the construction of biomass and numerical spectra because the gear employed is suited to comprehensive sampling of broad windows in the community spectrum (Peters 1983). However, there are technological limitations with any single type of sampling gear and it is only possible to sample a partial spectrum with any single gear type.

Lawton (1989) has pointed out that the range of body sizes included in biomass spectra may influence their form and has highlighted possible biases on the shape of spectra which would be introduced if population abundance of rare species is poorly estimated or if density estimates are based on arbitrary areas rather than habitat areas. The RMT 25 appears to effectively sample pelagic species spanning 4 orders of magnitude of body mass and in terms of energy flow rare species are unimportant. But sampling on a scale appropriate to the scale of habitat occupied by different species is problematic using the methods applied here which will generate spectra that can be expected to vary temporally according to the migration patterns of the individual species.

In a related paper the structure of the nekton community approximately $10 \mathrm{n}$ miles south of the Antarctic Polar Front (APF) in the IFZ of the oceanic Scotia Sea and the slope region of the South Georgia shelf (SGS) has been described by Piatkowski et al. (1994; this volume). In this paper we construct biomass and numerical spectra for the nekton communities in these 2 areas and examine aspects of production and energetics of the predator component of the pelagic system. Marine biomass spectra presented in the literature have generally been composites derived from various data sources in order to examine the whole ecosystem (e.g. Boudreau \& Dickie 1992). Terrestrial spectra on the other hand have generally focussed on particular communities or taxonomic groups and have been derived from data collected with a particular sampling technique or census method (e.g. Blackburn et al. 1993). Here we adopt a single sampling tool in the marine context in order to examine the utility of partial biomass spectra for characterising systems in a way that facilitates comparison between regions in terms of energy flux, in addition to conventional taxonomic methods.

We consider the majority of the predatory nektonic species but the gear we employed does not adequately sample the smaller members of the micronekton, particularly the amphipods and copepods, nor is it suitable for catching adults of the large active nektonic species such as the ommastrephid squids.

\section{METHODS}

Sampling. Nekton samples were collected with the British Antarctic Survey's opening/closing rectangular midwater trawl with $25 \mathrm{~m}^{2}$ aperture (RMT 25) based on Baker et al.'s (1973) design and described by Piatkowski et al. (1994). Sampling took place in austral summer 1991 approximately $10 \mathrm{n}$ miles south of the APF in the oceanic Scotia Sea (Stn 1; 13 to 15 January) and south of the APF over the slope of the South Georgia Shelf (Stn 2; 28 to 30 January). Net hauls were taken within 2 rectangles defined by $57^{\circ} 03.8^{\prime} \mathrm{S}$ to $57^{\circ} 08.7^{\prime} \mathrm{S}$, $55^{\circ} 08.6^{\prime} \mathrm{W}$ to $55^{\circ} 25.9^{\prime} \mathrm{W}$ ( $\left.\mathrm{Stn} 1\right)$ and $53^{\circ} 22.5^{\prime} \mathrm{S}$ to $53^{\circ} 39.1^{\prime} \mathrm{S}, 38^{\circ} 31.9^{\prime} \mathrm{W}$ to $38^{\circ} 55.7^{\prime} \mathrm{W}$ (Stn 2). Each $200 \mathrm{~m}$ layer from $0 \mathrm{~m}$ to $1000 \mathrm{~m}$ was sampled in both day and night, defined by sunrise and sunset. The duration of a standard haul was $2 \mathrm{~h}$. The mean volume filtered during each $2 \mathrm{~h}$ haul was $260000 \pm$ $48000 \mathrm{~m}^{3}$. Flowmeter data were used to correct all samples to either a standard volume of $100000 \mathrm{~m}^{3}$ or a standard area of $1 \mathrm{~m}^{2}$.

Treatment of samples. Nektonic organisms $(>10 \mathrm{~mm}$ in length or diameter) were identified to the lowest posssible taxonomic unit. Siphonophores, chaetognaths, polychaetes, small pteropods, small amphipods and copepods occurred regularly in the samples but were considered too small to be quantitatively sampled by the RMT 25 and so were discarded after sorting. The total number of each nektonic species was recorded and total volume of each species in each $200 \mathrm{~m}$ depth layer determined by displacement.

Treatment of data. We are considering here a restricted size range of organisms from within the full ecosytem spectrum. Boudreau \& Dickie (1992) discussed various aspects of the construction of biomass spectra; here we construct the spectra using the basic untransformed allometric form (Eq. 1).

Biomass and numerical spectra for day and night at each station for the whole water column from 0 to $1000 \mathrm{~m}$ were generated from data on mean individual volume (approximately equivalent to wet mass: $1 \mathrm{ml}=$ $1 \mathrm{~g}$ ) of each species. Data for mean individual volume for each species were collected for day and night at each station so that differences in the mean size of species sampled in each light regime and geographical area are reflected in the spectra. Wet mass was converted to dry mass using data given by Clarke (1980), Clarke et al. $(1985,1992)$ and Donnelly et al. (1990) for crustaceans, cephalopods, gelatinous forms, polychaetes and mesopelagic fishes. Percent water content of pteropods and nemerteans was assumed to be the same as for polychaetes.

Spectra were also derived separately for the 3 major nektonic groups, fish, crustacea and gelatinous forms which included the salps and cnidarians. 
Statistical procedures were performed using the Minitab statistical package (Ryan 1985).

\section{RESULTS}

The spectral distribution of size as wet mass for the nekton community, expressed as number per unit volume in each $200 \mathrm{~m}$ depth layer from 0 to $1000 \mathrm{~m}$, is shown in Fig. 1. The most conspicuous difference between the Antarctic Polar Front (Stn 1) and the South Georgia Shelf Break (Stn 2) was the higher total biomass at Stn 1 which was attributed to dense concentrations of salps (Piatkowski et al. 1994). These grazers were replaced by euphausiids at Stn 2 . Because of the variation in the size structure of the community between day and night, which is probably caused by a combination of migratory effects and differential net avoidance between day and night, the data for day and night are considered separately when constructing biomass and numerical spectra.

The $\log _{10}$-transformed biomass spectra of the nekton community for the whole water column, during day and night to a depth of $1000 \mathrm{~m}$, are shown in Fig. 2 and the associated statistical data are presented in Table 1. At both stations the linear relationship between $\log _{10}$ biomass density and $\log _{10}$ individual body mass was strongly positive. There is some evidence that the slope was steeper in the community sampled at night at Stn 1. These slopes show that the average biomass density $(B / A)$ scales as $M^{0.53}$ to $M^{0.80}$. The data for one particular group, the salps, were poorly fitted by these relationships. This group was excluded from an analysis of covariance which indicated that the slopes were

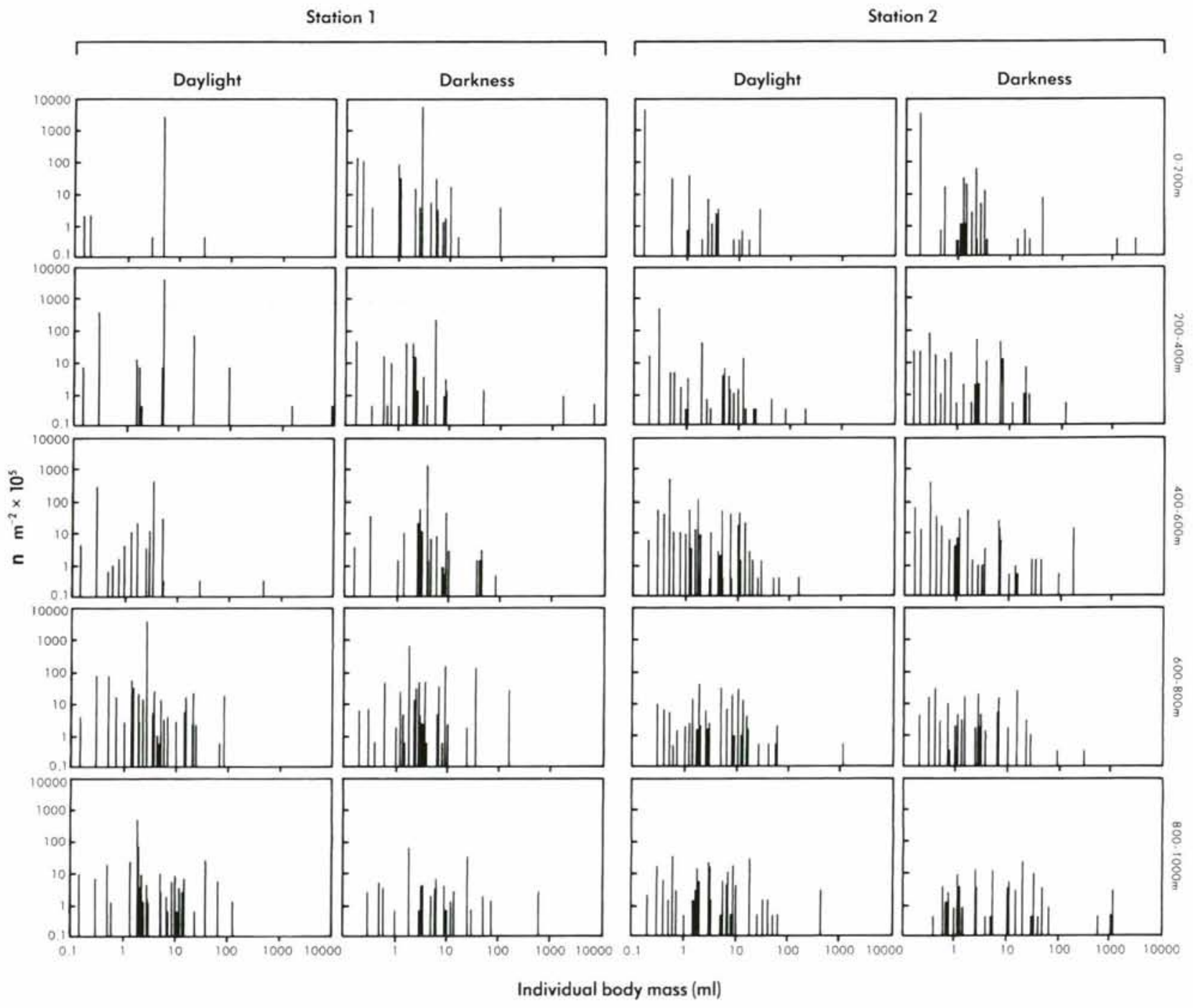

Fig. 1. Spectral distribution of size, as wet mass, for the nekton community sampled with the RMT 25 during day and night in $200 \mathrm{~m}$ layers between 0 and $1000 \mathrm{~m}$ at Stn 1 ( $10 \mathrm{n}$ miles south of the Antarctic Polar Front) and Stn 2 (South Georgia shelf break) 
not significantly different $(F=0.85, \mathrm{p}=$ 0.466) and assuming a constant slope the intercepts were also not significantly different $(F=0.33, p=0.804)$. An overall regression equation for all the data was calculated:

$$
\begin{gathered}
a=-1.982 \pm 0.054 \quad b=0.611 \pm 0.066 \\
\left(r^{2}=0.28, F_{1.216}=85.58, p<0.0001\right) .
\end{gathered}
$$

Inclusion of the salps did not affect the conclusions of this analysis $(a=-1.964$ $\pm 0.0567, b=0.593 \pm 0.069$ ) .

Biomass density of the nekton community in each area was thus dominated by larger animals. Biomass relationships with individual dry mass were not significantly different between the 2 stations despite the fact that species composition was different, at least in the upper water column, and wet mass standing crop was considerably greater at Stn 1 (Piatkowski et al. 1994).

The numerical spectra for the nekton community in both areas, during day and night, are shown in Fig. 3 and the associated statistical data are presented in Table 1. Slopes (b) were similar for each regression apart from the Stn 1 night data. In this case correlation was not significant at the $95 \%$ confidence level. The slopes for the data where there was significant correlation suggest that $N / A$ scales with size as $M^{-042}$ to $M^{-0.46}$

Biomass and numerical spectra for the fish, crustacean and gelatinous groups in the community were analysed independently. The results are represented by the regression data in Table 2. Correlation between $\log _{10} N / A, \log _{10} B / A$ and $\log _{10} M$ was non-significant at each station in day and night for the gelatinous community. The fish biomass spectra showed the same trends as the total nekton spectra although the slopes for the regressions were mostly steeper, indicating that the larger fish species dominate biomass and production to a greater extent than in the community as a whole, relative to the smaller species. Correlation between $\log _{10} N / A$ and $\log _{10} M$ was non-significant in most cases for the fish data, but in one instance the correlation was significant and the regression constants were similar to those for the numerical spectra for the whole community. Correlation between $\log _{10} N / A, \log _{10} B / A$
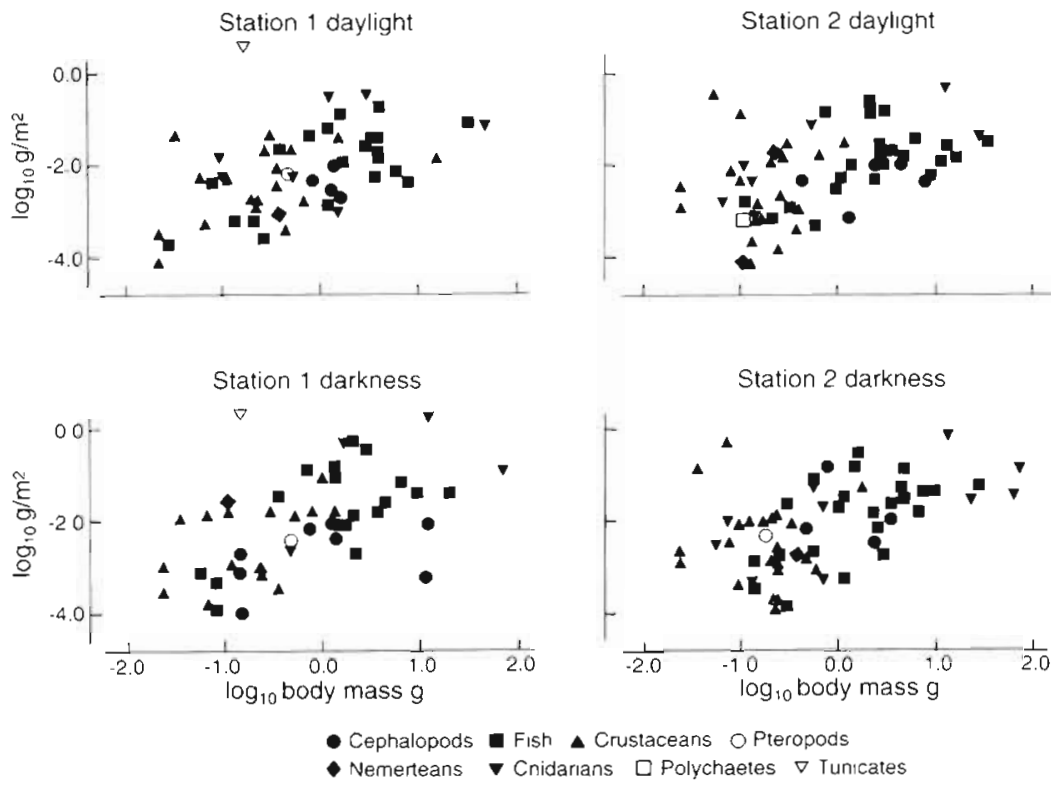

Fig. 2. Biomass spectra for the nekton community sampled with the RMT 25 during day and night between 0 and $1000 \mathrm{~m}$ at Stn 1 (10 $\mathrm{n}$ miles south of the Antarctic Polar Front) and Stn 2 (South Georgia shelf break)

Table 1. Statistics for biomass and numerical spectra for 2 stations in the Scotia Sea (Antarctic Polar Frontal Zone and South Georgia Shelf Break). The regression coefficients $\left( \pm\right.$ SD) are for the equations: $\log _{10} B / A=a+b \log _{10} M$ and $\log _{10} D / A=a+b \log _{10} M$ where $B / A$ is dry biomass density $\left(\mathrm{g} \mathrm{m}^{-2}\right), M$ is individual dry mass $(\mathrm{g})$ and $D / A$ is population density $\left(\mathrm{n} \mathrm{m}^{-2}\right)$. ns: not significant

\begin{tabular}{|lccccc|}
\hline \multicolumn{2}{c}{$a$} & $b$ & $r^{2}$ & df & $p<$ \\
\hline Biomass spectrum & & & & \\
Stn 1 & & & & \\
Day & $-1.99 \pm 0.12$ & $0.58 \pm 0.15$ & 0.234 & 52 & 0.01 \\
Night & $-1.81 \pm 0.13$ & $0.74 \pm 0.16$ & 0.320 & 44 & 0.01 \\
Stn 2 & & & & & \\
Day & $-2.03 \pm 0.11$ & $0.54 \pm 0.13$ & 0.223 & 60 & 0.01 \\
Night & $-2.00 \pm 0.11$ & $0.55 \pm 0.13$ & 0.240 & 58 & 0.01 \\
Numerical spectrum & & & & \\
Stn 1 & & & & & \\
Day & $-1.99 \pm 0.12$ & $-0.42 \pm 0.15$ & 0.139 & 52 & 0.01 \\
Night & $-1.81 \pm 0.13$ & $-0.26 \pm 0.16$ & 0.055 & 44 & $\mathrm{~ns}$ \\
Stn 2 & & & & & \\
Day & $-2.03 \pm 0.11$ & $-0.46 \pm 0.13$ & 0.173 & 60 & 0.01 \\
Night & $-2.00 \pm 0.11$ & $-0.45 \pm 0.12$ & 0.178 & 58 & 0.01 \\
\hline
\end{tabular}

and $\log _{10} M$ was non-significant in several cases among the data for crustaceans, but in instances where there was significant correlation the regression constants were similar to those for the total spectra.

The biomass spectra presented here can be used to generate the relative rate of biomass and heat production by each of the major nekton groups at the 2 stations. For this purpose production was calculated on the basis of $P / B$ scaling with $M^{-0.33}$ and $M^{-0.38}$ and 

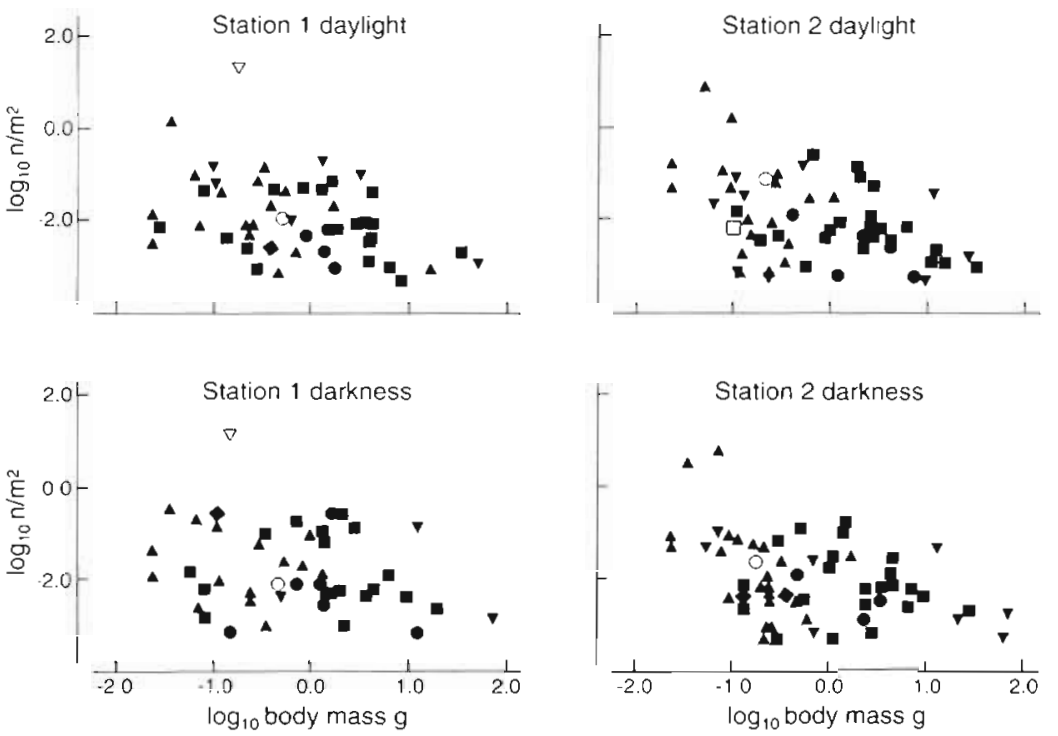

Fig. 3. Numerical spectra for the nekton community sampled with the RMT 25 during day and night between 0 and $1000 \mathrm{~m}$ at Stn $1(10 \mathrm{n}$ miles south of the Antarctic Polar Front) and Stn 2 (South Georgia shelf break). Symbols as for Fig. 2

strephid squids will also be sampled poorly by the net because of avoidance (Piatkowski et al. 1994). With these limitations of the sampling gear in mind however, some general statements can be made regarding the biomass spectra sampled by the net.

The partial spectrum of the pelagic ecosystem presented here focusses on the nekton community which, apart from the salps at Stn 1, are mostly predators. Nekton biomass density increased with individual body mass at both stations. Although the relationship, based largely on temperate species, between production and biomass used here to estimate the production characteristics of the community must be viewed with some caution, the data provide evidence that production is dominated by the larger animals. Similarly the individual body mass exponents for biomass density, when compared with the well established mass

$U / M$ scaling with $M^{-0.25}$ and $M^{-0.33}$. These exponents were chosen to represent the limits of the range of published values (Peters 1983, Boudreau \& Dickie 1989). Spectra for night only were used in the calculations as they are less influenced by problems of net avoidance by faster swimming organisms and so are probably more representative of community composition. The calculated values for relative standing crop biomass $(B / A)$ and rates of production $(P)$ and heat production $(U)$ for each nektonic group are given in Table 3 . The 2 stations differ mainly in the dominance of salps at Stn 1 where they represented $34 \%$ of the dry weight biomass as compared to $<1 \%$ at $\mathrm{Stn} 2$. The allometric calculations show that at Stn 1 the major contributor to turnover were the salps followed by fishes and cnidarians. At Stn 2 the most important group was the crustaceans followed again by fishes and cnidarians. Within the groups dominating the standing crop biomass it is clear that biomass per unit area does not reflect turnover.

\section{DISCUSSION}

The RMT 25 net, with its large mesh size in the front panels, undoubtedly underestimates the smaller nektonic groups. Although a number of siphonophores, chaetognaths, polychaetes, small pteropods, small amphipods and large copepods were caught these were not included in the spectra presented here. Similarly the larger, fast swimming species such as omma- exponent for rate of energy utilisation, provide good evidence that energy flow in the nekton community sampled with the RMT 25 was similarly dominated by the larger animals at both stations. When the biomass and numerical spectra were divided according to the major groups contributing to the biomass, the significant relationships between biomass density and numerical density were lost, except in the case of the biomass spectrum of the fishes.

It is evident that a community dominated, in terms of production and energy flow, by larger size groups or species of animals could not be sustained unless the community exploits a resource from outside its own window in the spectrum of biomass. The recorded size ratios of predators to prey generally cover 3 to 6 orders of magnitude (Boudreau \& Dickie 1992). Total biomass spectra described for other marine ecosystems are characterised by secondary structure comprising a series of domes or peaks in the biomass spectrum separated by distinct troughs where certain sizes of organisms are absent from the system (Schwinghamer 1981, 1985, Boudreau \& Dickie 1992). We conclude that the community, sampled with the RMT 25 at both stations described in this paper, represents the rising left-hand side of such a dome. This appears consistent with the spectra obtained by Witek \& Krajewska-Soltys (1989) for the phytoplankton-zooplankton community of the Antarctic Peninsula region. Dominance by relatively large organisms of the partial spectrum sampled by the RMT 25 suggests that there are few predator/prey 
interactions within this partial spectrum because there are too few smaller organisms to sustain predation by the larger forms. The species present in this partial spectrum probably prey on organisms forming

Table 2. Statistics for biomass and numerical spectra for fish, crustaceans and gelatinous nekton for 2 stations in the Scotia Sea (Antarctic Polar Frontal Zone and South Georgia Shelf Break). The regression coefficients ( \pm SD) are for the equations: $\log _{10} B / A=a+b \log _{10} M$ and $\log _{10} D / A=a+b \log _{10} M$ where $B / A$ is dry biomass density $\left(\mathrm{g} \mathrm{m}^{-2}\right), M$ is individual dry mass $(\mathrm{g})$ and $D / A$ is population density $\left(\mathrm{n} \mathrm{m}^{-2}\right)$

\begin{tabular}{|c|c|c|c|c|c|}
\hline & $a$ & $b$ & $r^{2}$ & $\mathrm{df}$ & $\mathrm{p}<$ \\
\hline \multicolumn{6}{|c|}{ Fish biomass spectrum } \\
\hline \multicolumn{6}{|c|}{ Stn 1} \\
\hline Day & $-2.11 \pm 0.15$ & $0.77 \pm 0.20$ & 0.448 & 19 & 0.01 \\
\hline Night & $-1.83 \pm 0.18$ & $0.89 \pm 0.26$ & 0.406 & 17 & 0.01 \\
\hline \multicolumn{6}{|l|}{ Stn 2} \\
\hline Day & $-1.92 \pm 0.15$ & $0.53 \pm 0.21$ & 0.218 & 22 & 0.05 \\
\hline Night & $-2.02 \pm 0.17$ & $0.85 \pm 0.27$ & 0.327 & 20 & 0.01 \\
\hline \multicolumn{6}{|c|}{ Fish numerical spectrum } \\
\hline \multicolumn{6}{|c|}{ Stn 1} \\
\hline Day & $-2.11 \pm 0.15$ & $-0.22 \pm 0.20$ & 0.065 & 19 & ns \\
\hline Night & $-1.83 \pm 0.18$ & $-0.11 \pm 0.26$ & 0.010 & 17 & ns \\
\hline \multicolumn{6}{|l|}{ Stn 2} \\
\hline Day & $-1.93 \pm 0.15$ & $-0.47 \pm 0.21$ & 0.185 & 22 & 0.05 \\
\hline Night & $-2.02 \pm 0.17$ & $-0.16 \pm 0.27$ & 0.016 & 20 & ns \\
\hline \multicolumn{6}{|c|}{ Crustacean biomass spectrum } \\
\hline \multicolumn{6}{|c|}{ Stn 1} \\
\hline Day & $-2.02 \pm 0.24$ & $0.61 \pm 0.26$ & 0.241 & 17 & 0.05 \\
\hline Night & $-1.88 \pm 0.34$ & $0.73 \pm 0.36$ & 0.245 & 13 & ns \\
\hline \multicolumn{6}{|l|}{ Stn 2} \\
\hline Day & $-2.31 \pm 0.49$ & $0.07 \pm 0.54$ & 0.010 & 19 & ns \\
\hline Night & $-2.68 \pm 0.41$ & $-0.27 \pm 0.45$ & 0.180 & 20 & 0.05 \\
\hline \multicolumn{6}{|c|}{ Crustacean numerical spectrum } \\
\hline \multicolumn{6}{|c|}{ Stn 1} \\
\hline Day & $-2.02 \pm 0.24$ & $-0.39 \pm 0.26$ & 0.113 & 17 & ns \\
\hline Night & $-1.88 \pm 0.34$ & $-0.26 \pm 0.36$ & 0.041 & 13 & ns \\
\hline \multicolumn{6}{|l|}{ Stn 2} \\
\hline Day & $-2.31 \pm 0.49$ & $-0.93 \pm 0.54$ & 0.137 & 19 & ns \\
\hline Night & $-2.68 \pm 0.41$ & $-1.27 \pm 0.46$ & 0.281 & 20 & 0.02 \\
\hline \multicolumn{6}{|c|}{ Gelatinous biomass spectrum } \\
\hline \multicolumn{6}{|l|}{ Stn 1} \\
\hline Day & $-1.32 \pm 0.45$ & $0.13 \pm 0.52$ & 0.010 & 6 & ns \\
\hline Night & $-0.85 \pm 0.52$ & $0.23 \pm 0.50$ & 0.051 & 4 & ns \\
\hline \multicolumn{6}{|l|}{ Stn 2} \\
\hline Day & $-1.98 \pm 0.32$ & $0.66 \pm 0.32$ & 0.376 & 7 & ns \\
\hline Night & $-1.91 \pm 0.26$ & $0.55 \pm 0.22$ & 0.440 & 8 & ns \\
\hline \multicolumn{6}{|c|}{ Gelatinous numerical spectrum } \\
\hline \multicolumn{6}{|c|}{$\operatorname{Stn} 1$} \\
\hline Day & $-1.32 \pm 0.45$ & $-0.87 \pm 0.52$ & 0.318 & 6 & ns \\
\hline Night & $-0.85 \pm 0.52$ & $-0.77 \pm 0.50$ & 0.375 & 4 & ns \\
\hline \multicolumn{6}{|l|}{ Stn 2} \\
\hline Day & $-1.98 \pm 0.32$ & $-0.34 \pm 0.32$ & 0.139 & 7 & ns \\
\hline Night & $-1.91 \pm 0.26$ & $-0.45 \pm 0.22$ & 0.339 & 8 & ns \\
\hline
\end{tabular}

another dome further to the left on the full spectrum. This conclusion is supported, at least in the case of the mesopelagic fishes, by data showing that diet in this group is largely dominated by copepods (Kock 1992).

Although the concept of predation by a large category of organisms on a smaller category is intuitive, conventional analysis of community structure (Piatkowski et al. 1994) does not illustrate the size relationships that exist or reveal anything about energy flow in the system. The simple concept of a continuous spectrum of biomass, with no discontinuities, predicts a mass exponent of zero for biomass density. Our data depart from this simple model emphasizing the limitations of the analysis of the nekton community by taxonomic groups (Piakowski et al. 1994) and the fact that the community should not be considered in isolation from the rest of the system. This is particularly important in the analysis of food web structure (see Pimm 1992). Clearly there are interactions within the nekton but the biomass spectra approach shows that major inputs of energy are required to maintain the community, that there are probably relatively few internal predator-prey interactions and that there are important trophic links that have not been sampled.

It is not possible to determine whether the rising biomass spectrum described here occurs at a discontinuity in the spectrum or whether there are overlapping size groups which have not been properly sampled. Assemblages will have an apparent positive slope biomass spectrum, of the form observed here, if the smaller size classes are poorly sampled. Biomass spectra indicate the degree of isolation of a particular assemblage and the extent to which the larger organisms within the assemblage are supported by others within the spectrum sampled. In the pelagic system sampled in the present study there is probably no group that would fill the lower size classes, suggesting that the apparent discontinuity in the spectrum is not artifactual.

It is not immediately apparent what mechanisms generate dome structure in the pelagic biomass spectrum, although there are suggested mechanisms for multi-modal structure in the benthos (Schwinghamer 1985). Witek \& Krajew- 
Table 3. Proportional contribution to biomass production $(P)$, heat production $(U)$ and biomass density $(B / A)$ of the different groups of nektonic organisms at 2 stations in the Scotia Sea

\begin{tabular}{|c|c|c|c|}
\hline & $\% P$ & $\% U$ & $\% B / A$ \\
\hline \multicolumn{4}{|l|}{ Stn 1 (night) } \\
\hline Tunicates & $58.5-61.8$ & $53.0-58.5$ & 34.0 \\
\hline Fish & $17.7-19.0$ & $19.0-20.9$ & 25.5 \\
\hline Coelenterates & $15.9-17.9$ & $17.9-21.1$ & 36.7 \\
\hline Crustaceans & $4.2-4.3$ & $4.1-4.2$ & 3.2 \\
\hline Cephalopods & $0.3-0.4$ & $0.4-0.4$ & 0.5 \\
\hline Pteropods & $0.1-0.1$ & $0.1-0.1$ & 0.1 \\
\hline \multicolumn{4}{|l|}{ Stn 2 (night) } \\
\hline Crustaceans & $55.2-59.6$ & $47.7-55.2$ & 25.1 \\
\hline Fish & $25.4-27.6$ & $27.6-31.1$ & 37.5 \\
\hline Coelenterates & $13.9-16.0$ & $16.0-20.0$ & 36.2 \\
\hline Cephalopods & $0.6-0.6$ & $0.6-0.7$ & 0.8 \\
\hline Pteropods & $0.3-0.3$ & $0.3-0.3$ & 0.2 \\
\hline Nemerteans & $0.1-0.1$ & $0.1-0.1$ & 0.1 \\
\hline Polychaetes & $0.1-0.1$ & $0.1-0.1$ & 0.1 \\
\hline
\end{tabular}

ska-Soltys (1989) considered some of the various aspects which might generate disturbance in phytoplankton-zooplankton biomass spectra in high latitude pelagic systems. Possibly in environments where primary productivity is highly seasonal there is an evolutionary choice between a short generation time with resting stages during the winter season, implying small size, and a longer generation time with an overwintering energy storage strategy. Selection would tend towards evolution of large body size in the latter because of the relatively low metabolic rate of larger organisms, as implied by the scaling of metabolism with $M^{0.75}$, and hence reduced rate of depletion of metabolic reserves at larger sizes (Brown \& Maurer 1986). The within season processes of growth and reproduction also tend to generate spectra dominated by large organisms. For example, the larval production of the smaller groups will not have been sampled by the net used in this study. Spatial and temporal separation of production processes will also generate disturbances in the spectra.

If the data presented here represent the background status in the Antarctic IFZ nekton, with relatively low rates of energy turnover, then the spectra we describe may be perturbed when conditions generate high concentrations of myctophid fishes and ommastrephid squids. Under these conditions the slope of the biomass and numerical spectra may be altered for the duration of the events which generate local levels of high turnover. Primary productivity in the IFZ is low despite the fact that nutrient levels are generally high (Hempel 1985). High wind stress probably maintains a deep mixed layer for much of the time in the IFZ (Marchant \& Murphy 1994) but when local conditions allow stratification the production events that follow must cause perturbations in the total biomass spectra which will in turn influence the partial spectra comprising the nekton.

The biomass, on a dry mass basis, at the oceanic Stn 1 was dominated, in order of importance, by cnidarians, salps and fishes and at the South Georgia Slope Stn 2 it was dominated by fishes, cnidarians and crustaceans (Table 3). Essentially the same pattern of dominance by these groups was apparent on a wet weight basis at both stations (Piatkowski et al. 1994). At the grazing level it is notable that at Stn 1 the herbivores were predominantly salps whilst at Stn 2 they were mostly euphausiids. Acoustic records showed that there were no large aggregations of mesopelagic fishes or cephalopods at the stations occupied and so the nekton biomass spectra presented here represent what might be considered background values. Close similarity between the nekton community structure between the 2 areas, especially in the deeper layers $(>400 \mathrm{~m})$, suggests that the permanently ice-free zone of the Scotia Sea may be relatively homogeneous in this respect but the $>3 \times$ difference in biomass density is evidence of patchy distribution in the relative partitioning of the production between groups, reflected in this instance by a large biomass of salps at Stn 1 . In the generally less productive conditions at the oceanic site, salps may be adapted to respond faster to a rare production event by virtue of asexual reproduction than the sexually reproducing herbivorous crustaceans.

The comparison of the 2 stations using the biomass spectra approach indicates that the apparent large differences in wet weight between the 2 stations were much less pronounced in terms of dry weight and that the 2 stations showed a similar community structure apart from the presence of salps at Stn 1. So, although the species differ between the 2 stations the production at the 2 stations may not be very different in terms of the general pattern of energy flux. This suggests that different species occupy similar niches on the 2 stations thus generating the same basic size structure. The calculations based on the size spectra indicate that generally the major groups show a similar level of turnover on the 2 stations. The consistent slope between the 2 sites may also indicate that the environment is similar resulting in the same basic community structure with respect to size.

There is a lot of variance in the data not explained by the fitted biomass spectra as shown by the relatively low values of $r^{2}$. This means that the statistical power to resolve differences in the biomass spectra between different regions is weak. The general conclusions obtained will not be sensitive to these effects but only very gross differences in community composition would be identified with this type of analysis. To further assess the usefulness of biomass spectra for 
resolving differences in community composition and ecosystem operation, data are required for a wider size-range of organisms and these need to be collected over temporal and spatial scales relevant to the organisms sampled.

The taxonomic differences between the 2 stations have consequences for higher trophic levels. Suspension-feeding gelatinous forms (tunicates), in contrast to planktonic crustaceans, largely form an energetic dead end supporting few predators. Their success in certain situations may derive from their ability to exploit smaller particles (Flood et al. 1992), at lower trophic levels, and from a life cycle featuring alternation of generations. This allows rapid population growth when conditions are favourable at the expense of the genetic consequences of asexual reproduction.

Some of the problems of generating biomass spectra have been discussed by Boudreau \& Dickie (1992). The spectra calculated above were generated by aggregating data over a range of species. Thus, the calculations generated above must be considered as general descriptions of the community processes. The key relationships used in the calculations are those of $P / B$ scaling to $M^{-0.36}, U$ scaling to $M^{0.75}$ and $P / U$ scaling to $M^{0}$. The general conclusions generated above are not sensitive to variation in these parameters. The salps (Salpa thompsoni) do not fit very well into the size-based description of the stations. They were probably the only major herbivore among the nekton sampled effectively with the RMT 25 . They can represent very high biomass in terms of wet weight but they have a relatively small individual dry weight. On the basis of the allometric relations used they were a major factor in turnover at $S \operatorname{tn} 1$. The mass exponent for clearance rate in $S$. thompsoni (Huntley et al. 1989) meets empirical expectations (Peters 1983) but other rate processes of salps may be poorly represented by the basic allometric relationships of the form used here and further detail is required on their energy budget. Given their large size (linear dimensions) for small body weight they may be an unusual component of the community. Similarly, by virtue of a body size that is increased by having a high water content, the cnidarians functionally occupy a higher position in the biomass spectrum, and probably the pelagic food chain, than their dry weight would imply.

Much of the debate over the usefulness of biomass spectra is being conducted in the non-marine ecological literature (Lawton 1989). Evidence for the usefulness of terrestrial spectra appears equivocal and many terrestrial spectra that have been analysed are less well defined than in marine systems (Griffiths 1992, Blackburn et al. 1993). Marine analyses often use biomass/size class rather than biomass/species data and the biomass/species relationships considered by
Blackburn et al. (1993) have much lower $\mathrm{r}^{2}$ values than observed in this study. As discussed above, sampling a restricted component of a community will generate a limited view of the system. Obtaining relationships that follow theoretical energetically constrained patterns probably requires that a relatively wide range of size classes and predator-prey interactions be represented in the samples. The size relationships in partial biomass spectra may be variable but this does not reduce the utility of using the spectra to consider the patterns of energy usage and production in the assemblage.

Statistical methodologies used in the calculation of biomass spectra are the subject of current debate. (Griffiths 1992, Blackburn et al. 1993). Measurement of organism size involves an error, therefore it is argued that a Reduced Major Axis (RMA) rather than an ordinary least squares (OLS) regression should be applied to the relationship between individual biomass and biomass density. Use of RMA requires some assumption or knowledge about the ratio of the variances in the dependent and independent variables. It seems likely that in constructing biomass spectra, errors in measurement of biomass density will be much greater than the errors associated with measurement of individual biomass. The RMA as applied by Griffiths (1992) and Blackburn et al. (1993) in this case would give a poorer estimator of the true slope than the OLS. This is supported by the observation that using OLS there is a consistent relationship between numerical and biomass spectra of approximately $M^{1}$ which is of the order expected (Peters 1983). The use of the RMA regression for the biomass spectrum would tend to further emphasise the importance of large organisms in the energy fluxes.

Acknowledgements. The series of RMT 25 hauls described in this paper were the last samples to be taken aboard the RRS 'John Biscoe' prior to her decommissioning by the British Antarctic Survey in 1991. It is therefore an opportune time to gratefully thank the ship's company at that time for their contribution to this research programme. In particular we thank the Captain, Chris Elliot, the Chief Engineer, Simon Taylor, the 1st, 2nd and 3rd Officers, Robin Plumley, John Harper and Trevor Boult, and the Bosun and Bosun's Mate, John Summers and George Stewart. Many thanks to the Chief Scientist, Jon Watkins, and the members of the Pelagic Ecosystem group of the Marine Life Sciences Division who gave much time at sea launching and recovering the RMT 25 and sorting the contents of numerous codends. We are grateful to Drs Renate Haass, Hans-Georg Andres, Francesco Pages, Volker Siegel, Ludwig Tiefenbacher and Prof. Siebrecht van der Spoel for their help in identifying various nektonic species. This paper was written whilst Paul Rodhouse and Uwe Piatkowski were in receipt of grants made under the BritishGerman Academic Research Collaborative programme of the British Council and the Deutscher Akademischer Austauschdienst (AT 313-ARC-VI-92/65). 


\section{LITERATURE CITED}

Adams, N. J., Klages, N. T. (1987). Seasonal variation in the diet of the king penguin (Aptenodytes patagonicus) at sub-antarctic Marion Island. J. Zool. 212: 303-324

Ainley, D. G., Fraser, W. R., Smith, W. O. Jr, Hopkins, T. L., Torres, J. J. (1991). The structure of upper level pelagic food webs in the Antarctic: effect of phytoplankton distribution. J. mar. Syst. 2: 111-122

Baker, A. de C., Clarke, M. R., Harris, M. J. (1973). The N.I.O. combination net (RMT $1+8$ ) and further developments of rectangular midwater trawls. J. mar. biol. Ass. U.K. 53: $167-184$

Banse, K., Mosher, S. (1980). Adult body mass and annual production/biomass relationships of field populations. Ecol. Monogr. 50: 355-379

Bayne, B. L., Newell, R. C. (1983). Physiological energetics of marine molluscs. In: Saleudin, A. S. M., Wilbur, K. M. (eds.) The Mollusca, Vol. 4, Physiology, Part 1. Academic Press, New York, p. 407-515

Blackburn, T. M., Brown, V. K., Doube, B. M., Greenwood, J. J. D., Lawton, J. H., Stork, N. L. (1993). The relationship between abundance and body size in natural animal assemablages. J. Anim. Ecol. 62: 519-528

Boudreau, P. R., Dickie, L. M. (1989). A biological model of fisheries production based on physiological and ecological scalings of body size. Can. J. Fish. Aquat. Sci. 46: 614-623

Boudreau, P. R., Dickie, L. M. (1992). Biomass spectra of aquatic ecosystems in relation to fisheries yield. Can. J. Fish. Aquat. Sci. 49: 1528-1538

Boudreau, P. R., Dickie, L. M., Kerr, S. R. (1991). Body-size spectra of production and biomass as system-level indicators of ecological dynamics. J. theor. Biol. 52: 329-339

Brown, J. H., Maurer, B. A. (1986). Body size, ecological dominance and Cope's rule. Nature 324: 248-250

Clarke, A. (1980). The biochemical composition of krill, Euphausia superba Dana, from South Georgia. J. exp. mar. Biol. Ecol. 43: 221-236

Clarke, A., Clarke, M. R., Holmes, L. J., Waters, T. D. (1985). Calorific values and elemental analysis of eleven species of oceanic squids (Mollusca: Cephalopoda). J. mar. biol. Ass. U.K. 65: 983-986

Clarke, A., Holmes, L. J., Gore, D. J. (1992). Proximate and elemental composition of gelatinous zooplankton from the Southern Ocean. J. exp. mar. Biol. Ecol. 155: 55-68

Croxall, J. P., Prince, P. A., Ricketts, C. (1985). Relationships between prey life-cycles and the extent, nature and timing of seal and seabird predation in the Scotia Sea. In: Siegfried, W. R., Condy, P. R., Laws, R. M. (eds.) Antarctic nutrient cycles and food webs. Springer-Verlag, Berlin, p. 516-533

Dickie, L. M., Kerr, S. R., Boudreau, P. R. (1987). Size-dependent processes underlying regularities in ecosystem structure. Ecol. Monogr. 57: 233-250

Donnelly, J., Torres, J. J., Hopkins, T. L., Lancraft, T. M. (1990). Proximate composition of Antarctic mesopelagic fishes. Mar. Biol. 106: 12-23

Filin, A. A., Gorchinsky, K. V., Kiseleva, V. M. (1991). Biomass of myctophids in the Atlantic sector of the Southern Ocean as estimated by acoustic surveys. SC-CAMLR-SSP/7. Commission for the Conservation of Antarctic Marine Living Resources, Hobart, Australia, p. 417-431

Flood, P. R., Deibel, D., Morris, C. C. (1992). Filtration of colloidal melanin from sea water by planktonic tunicates. Nature 355: 630-632

Foxton, P. (1966). The distribution and life history of Salpa thomposoni Foxton with observations on a related species
Salpa gerlachei. 'Discovery' Rep. 34: 1-116

Griffiths, D. (1992). Size, abundance and energy use in communities. J. Anim. Ecol. 61: 307-315

Hempel, G. (1985). On the biology of the Polar Seas especially the Southern Ocean. In: Gray, J. S., Christiansen, M. E. (eds.) Marine biology of polar regions and effects of stress on marine organisms. John Wiley, Chichester, p. 3-34

Hindell, M. A. (1988). The diet of the king penguin Aptenodytes patagonicus at Maquarie Island. Ibis 130: 193-203

Humphreys, W. F. (1979). Production and respiration in animal populations. J. Anim. Ecol. 48: 427-453

Huntley, M. E., Sykes, P. F., Marin, V. (1989). Biometry and trophodynamics of Salpa thompsoni Foxton (Tunicata: Thaliacea) near the Antarctic Peninsula in austral summer, 1983-1984. Polar Biol. 10: 59-70

Ikeda, T. (1985). Metabolic rates of epipelagic marine zooplankton. Mar. Biol. 85: 1-11

Ivleva, I. V. (1980). The dependence of crustacean respiration rate on body mass and habitat temperature. Int. Rev. ges. Hydrobiol. 65: 1-47

Jobling, M. (1993). Bioenergetics: feed intake and energy partitioning. In: Rankin, J. C., Jensen, F. B. (eds.) Fish ecophysiology. Chapman and Hall, London, p. 1-44

Kock, K. H. (1992). Antarctic fish and fisheries. Cambridge University Press, Cambridge

Koslov, A. N., Shust, K. V., Zemsky, A. V. (1991). Seasonal and interannual variability in the distribution of Electrona carlsbergi in the Southern Polar Front area (the north of South Georgia is used as an example). SC-CAMLR-SSP/7. Commission for the Conservation of Antarctic Marine Living Resources, Hobart, Australia, p. 337-367

Lawton, J. H. (1989). What is the relationship between population density and body size in animals. Oikos 55: 429-434

Lindeman, R. L. (1942). The trophic-dynamic aspect of ecology. Ecology 23: 399-418

Lubimova, T. G., Makarov, R. R., Shust, K. V., Lisovenko, L. A., Zemsky, V. A., Studenetskaya, I. S. (1983). Biological resources of the Southern Ocean. (In: Fishery utilization of the World Ocean.) TsNIITEIRKH, USSR, Ministry of Fisheries, Moscow, p. 18-32 (in Russian)

Mackintosh, N. A. (1934). Distribution of the macroplankton in the Atlantic sector of the Antarctic. 'Discovery' Rep. 9: $65-160$

McNeil, S., Lawton, J. H. (1970). Annual production and respiration in animal populations. Nature 225: 472-474

Mann, K. H., Field, J. G., Wulff, F. (1989). Network analysis in marine ecology: an assessment. In: Wulff, F., Field, J. G., Mann, K. H. (eds.) Network analysis in marine ecology: methods and application. Springer-Verlag, Berlin, p. 259-282

Marchant, H., Murphy, E. J. (1994). Interactions at the base of the Antarctic food web. In: El-Sayed, S. (ed.) Southern Ocean Ecology: the BIOMASS perspective. Cambridge University Press, Cambridge, p. 267-285

Peters, R. H. (1983). The ecological implications of body size. Cambridge University Press, Cambridge

Piatkowski, U., Rodhouse, P. G., White, M. G., Bone, D. G., Symon, C. (1994). Nekton community of the Scotia Sea as sampled by the RMT 25 during austral summer. Mar. Ecol. Prog. Ser. 112: 13-28

Pimm, S. L. (1992). The balance of nature. University of Chicago Press, Chicago

Ridoux, V. (in press). Diets and dietary segregation at subantarctic Crozet Islands. Mar. Ornithol.

Rodhouse, P. G. (1990). Cephalopod fauna of the Scotia Sea at South Georgia: potential for commercial exploitation and possible consequences. In: Kerry, K., Hempel, G. (eds.) 
Ecological change and the conservation of Antarctic ecosystems. Proc. 5th SCAR Symp. Antarct. Biol. SpringerVerlag, Berlin, p. 289-298

Rodhouse, P. G. (1991). Population structure of Martialia hyadesi (Cephalopoda: Ommastrephidae) at the Antarctic Polar Front and the Patagonian shelf, South Atlantic. Bull. mar. Sci. 49: 404-418

Rodhouse, P. G., Arnbom, T. R., Fedak, M. A., Yeatman, J., Murray, A. W. A. (1992a). Cephalopod prey of the southern elephant seal, Mirounga leonina L. Can. J. Zool. 70: $1007-1015$

Rodhouse, P. G., Clarke, M. R., Murray, A. W. A. (1987). Cephalopod prey of the Wandering Albatross Diomedea exulans. Mar. Biol. 96: 1-10

Rodhouse, P. G., Croxall, J. P., Prince, P. A. (1993). Towards an assessment of the stock of the ommastrephid squid Martialia hyadesi in the Scotia Sea: data from predators. In: Okutani, T., O'Dor, R., Kubodera, T. (eds.) Recent advances in cephalopod fishery biology. Tokai University Press, Tokyo, p. 433-440

Rodhouse, P. G., Prince, P. A. (1993). Cephalopod prey of the black-browed albatross at South Georgia. Polar Biol. 13: $373-376$

This article was submitted to the editor
Rodhouse, P. G., Prince, P. A., Clarke, M. R., Murray, A. W. A. (1990). Cephalopod prey of the grey-headed albatross Diomedea chrysostoma. Mar. Biol. 104: 353-362

Rodhouse, P. G., White, M. G., Jones, M. R. R. (1992b). Trophic relations of the cephalopod Martialia hyadesi (Teuthoidea: Ommastrephidae) at the Antarctic Polar Front, Scotia Sea. Mar. Biol. 114: 415-421

Rodhouse, P. G., Yeatman, J. (1990). Redescription of Martialia hyadesi Rochebrune and Mabille, 1889 (Mollusca: Cephalopoda) from the Southern Ocean. Bull. Br. Mus. nat. Hist. (Zool.) 56: 135-143

Ryan, B. F, Joiner, B. L., Thomas, A., Ryan, T. A. Jr (1985). Mintab handbook, 2nd edn. Duxbury Press, Boston

Schwinghamer, P. (1981). Characteristic size distributions of integral benthic communities. Can. J. Fish. Aquat. Sci. 38: 1255-1263

Schwinghamer, P. (1985). Observations on size-structure and pelagic coupling of some shelf and abyssal benthic communities. In: Gibbs, P. E. (ed.) Proc. 19th Eur. Mar. Biol. Symp. Cambridge University Press, Cambridge, p. 347-359

Witek Z., Krajewska-Soltys, A. (1989). Some examples of the epipelagic plankton size structure in high latitude oceans. J. Plankton Res. 11: 1143-1155

Manuscript first received: June 9, 1993

Revised version accepted: June 16, 1994 